K.Khelil ${ }^{1}$,

K. Saouchi ${ }^{1}$, Dr. Sc. (Tech.), Prof.,

D. Behloul ${ }^{2}$, Dr. Sc. (Tech.), Prof.
1 - University Badji Mokhtar - Annaba, Annaba, Algeria, e-mail: khadidjapra@gmail.com

2 - University Hadj Lakhdar - Batna, Batna, Algeria

\title{
EFFECT OF THE CHIRP ON INTERACTIONS OF PURE-CHIRPED SOLITONS
}

Purpose. To study the effect of the chirp on solitons interaction.

Methodology. To assess the influence of the chirp on solitons interaction, our study is focused on fundamental solitons modelled by the famous Nonlinear Schrodinger Equation (NLSE) and simulated using Fast Fourier Transform. Firstly, we discuss the influence of the chirp by setting different values of group velocity dispersion (GVD) of one fundamental soliton. Secondly, we introduce the chirp on two fundamental solitons close enough to create Kerr-induced non-linearity and in the absence of GVD we study its impact on their interaction. Finally, we apply the chirp for two fundamental solitons with different phases, amplitudes and order of solitons to compare its impact on interactions in all cases possible.

Findings. The chirp is useful to delete the interactions in the absence of GVD.

Originality. The originality is to use the chirp without GVD to separate two solitons that are subject to attraction or repulsion.

Practical value. This study illustrates that with the parameter of the group velocity dispersion $\beta_{2}=-25 \mathrm{ps}^{2} / \mathrm{km}$ and a chirp parameter equal to $C_{1}=0.5$ or $C_{2}=-0.5\left(C_{1}, C_{2}\right.$ are the chirp coefficients of the first and the second solitons respectively) an additional periodic compression is obtained. Later, we gradually decrease the GVD until its nullification; here we find a regular compression instead of the periodic one. Lastly, we study the influence of the chirp parameter on two adjacent fundamental solitons for the chirp parameter $C=2,3$ and 4 with different values of the bit rate $\tau=2$ and 3. Finally, we vary the initial parameters of the solitons such as the phase, the amplitude and the order of the solitons.

Keywords: solitons interaction, non-linearity, dispersion, optical fiber, transmission channel, temporal chirp

Introduction. In soliton transmission, the necessity of carrying massive information sending requires the propagation of multiple solitons at the same time in the so-called "soliton pulse train". As a carrier of the information, the soliton is named a bit, and by definition, the more the bit rate $B=1 / T_{B}$ increases, the better the communication is; on the other hand, the less the time interval $T_{B}$ between two consecutive solitons is, the higher the bit rate error is. Thus, the necessary temporal separation threshold is crossed and consequently harmful soliton interactions do appear. This Gordon-Haus temporal jitter effect has serious consequences on the optical soliton communication systems because it increases the bit rate error, limiting significantly the potential of the communication system [1, 2].

The propagation of solitons through the optical fiber can be modeled by the known non-linear Schrödinger equation. In the femtosecond regime, the propagation is described by the higher-order nonlinear Schrödinger (HNLS) equation derived by Kodama and Hasegawa [3]

$$
\begin{gathered}
\frac{\partial A(Z, T)}{\partial Z}+\frac{\alpha}{2} A-i \sum_{m=2}^{M} \frac{i^{m}}{m !} \beta_{m} \frac{\partial^{m} A}{\partial T^{m}}= \\
=+i \gamma\left[N^{2}|A|^{2} A+\frac{i}{\omega_{0}} \frac{\partial A}{\partial z}\left(|A|^{2} A\right)-T_{R} \frac{\partial|A|^{2}}{\partial T}\right],
\end{gathered}
$$

where $A(Z, T)$ is the slowly varying envelope of the optical soliton. In the same equation, the terms are respectively: fiber loss, the dispersion up to the $M^{\text {th }}$ order, Kerr nonlinearity, self-steepening, and Raman Effect, $\alpha$ is the fiber loss coefficient, $\omega_{0}$ is the carrier pulsation, $N$ is the soliton order, $\gamma$ is the coefficient of the nonlinear Kerr effect, and $T_{R}$ is the Raman resonant time constant; it is related to the Raman response function. $Z$ is the spatial coordinate representing the distance of transmission.

$T \equiv t-\beta_{1} Z$ is the temporal coordinate in delayed frame that moves at the group velocity $v_{g}$ of the propagating pulse. It should be noted that $\beta_{m}$ represents the dispersion parameters of the orders $m(m=1,2,3, \ldots, \infty)$.

For $m=1, \beta_{1}$ is the inverse of the group velocity described by the expression

$$
\beta_{1}=\frac{1}{c}\left(n+\omega \frac{d n}{d \omega}\right)=\frac{1}{v_{g}} .
$$

(C) Khelil K., Saouchi K., Behloul D., 2020
For $m=2, \beta_{2}$ is the $2^{\text {nd }}$ order group velocity dispersion (GVD) given by the expression

$$
\beta_{2}=\frac{d^{2} \beta(\omega)}{d \omega^{2}}=-\frac{1}{v_{g}^{2}} \frac{\partial v_{g}}{\partial \omega}=\frac{1}{c}\left(2 \frac{d n}{d \omega}+\omega \frac{d^{2} n}{d \omega^{2}}\right) .
$$

For $m=3, \beta_{3}$ is the third order dispersion (TOD) parameter.

On the other hand, the coefficient of the refractive index $n$ is composed of two parts: the coefficient of the linear refractive index $n_{0}=1.444$ for silica fibers, and the coefficient of the nonlinear refractive index $n_{2}=2.2 \cdot 10^{-20} \mathrm{~m}^{2} / \mathrm{W}$, and it is written as follows

$$
n=n_{0}+n_{2} I,
$$

where $I$ is the intensity of the injected pulse.

Secondly: $\gamma=n_{2} \omega_{0} / c A_{\text {eff }}$ is the coefficient of the nonlinear Kerr effect, whose value is $\gamma=1.0(\mathrm{~W} \cdot \mathrm{km})^{-1}$ at a wavelength: $\lambda_{0} \sim 1550 \mathrm{~nm}, A_{\text {eff }}$ is the effective area of the optical fiber, $\omega_{0}$ is the carrier pulsation.

For optical pulses in the picosecond regime, the higher order effects such as the third order and fourth order dispersion, self-steepening and delayed Raman response are neglected, so the pulses can be described using the simplified NLS model

$$
\frac{\partial A(Z, T)}{\partial Z}=-\frac{i}{2} \beta_{2} \frac{\partial^{2} A}{\partial T^{2}}+i N^{2} \gamma\left[|A|^{2} A\right] .
$$

If $N=1$, a fundamental conventional soliton is created because the nonlinearity exactly counterbalances the GVD. In this case, the solution obtained using the Fourier transform method for an initial injected pulse of secant hyperbolic type is

$$
A(z=0, T)=A_{0} \operatorname{sech}\left(\frac{T}{T_{0}}\right),
$$

where $T_{0}=5.0 \mathrm{ps}$ is the width of the impulsion; $A_{0}=\sqrt{P_{0}}=$ $=1.0 \mathrm{~W}$ is its amplitude.

Otherwise, if $N>1$, the soliton is called a higher order soliton. Its evolution in this case is periodically dependent on the fiber length. The physical interpretation of the periodicity is that the nonlinearity is greater than the GVD (the nonlinearity is $\mathrm{N}$ multiple of the GVD), for that it cannot be completely counterbalanced and the soliton propagates with a periodic shape.

So the solution becomes 


$$
A(z=0, T)=N^{2} A_{0} \operatorname{sech}\left(T / T_{0}\right)
$$

The soliton order is $N$, such as

$$
N^{2}=\gamma \cdot P_{0} \frac{T_{0}^{2}}{\left|\beta_{2}\right|}=\frac{L_{D}}{L_{N L}} .
$$

The nonlinear length is

$$
L_{N L}=\frac{1}{\gamma P_{0}} .
$$

The dispersive length is

$$
L_{D}=\frac{T_{0}^{2}}{\left|\beta_{2}\right|}
$$

The period of the soliton is

$$
Z_{0}=\frac{\pi}{2} \cdot \frac{T_{0}^{2}}{\left|\beta_{2}\right|},
$$

when the nonlinear phase shift is considered, the solution is written as follows

$$
A(z=0, T)=A_{0} \cdot \operatorname{sech}\left(T / T_{0}\right) \cdot \exp \left(i \cdot \hat{\theta}\left(T / T_{0}\right)\right),
$$

where $\hat{\theta}\left(T / T_{0}\right)$ is the temporal phase of the pulse.

When the phase of the pulse varies in a hyperbolic way over the time, its instantaneous frequency (derived from the phase) varies linearly over the time. This information on the instantaneous frequency is described by a parameter, called the coefficient of the chirp C. For this reason in the literature it is defined as the temporal dependency of the instantaneous frequency.

A particular case frequently encountered is that of a quadratic phase of the form

$$
\hat{\theta}\left(T / T_{0}\right)=\theta-\frac{C}{2}\left(T / T_{0}\right)^{2},
$$

where $\theta$ is the constant phase of the pulse.

If the initial pulse is chirped linearly, its profile is as follows

$$
A(z=0, T)=A_{0} \operatorname{sech}\left(T / T_{0}\right) \cdot e^{\left(-i \cdot(C / 2) \cdot\left(T / T_{0}\right)^{2}\right)} .
$$

The instantaneous frequency thus increases linearly with the time, so that the low frequencies are at the top of the pulse and the high frequencies on the falling edge of the pulse.

Indeed, the NLS equation is a partial differential linear equation, a reason why it is very difficult to solve analytically. Among a large number of numerical methods, we cite the Split Step Fourier Method, the Hirota method [4, 5], the Darboux transformation based on the Lax pair [6], the ansatz method [7], the Backlund transformation [8], the inverse scattering method [9], and so on.

The principle of the Split Step Fourier Method, the one we use for this paper, is to consider the nonlinear Schrödinger equation that can be written in the following form

$$
\frac{\partial A}{\partial Z}=(\hat{N}+\hat{D}) A
$$

where $\hat{N}$ and $\hat{D}$ represent the two operators nonlinear and linear respectively. If we take the equation (1), the operators are written as follows

$$
\hat{N}=i \gamma\left[|A|^{2}\right]
$$

and

$$
\hat{D}=-\frac{i}{2} \beta_{2} \frac{\partial^{2}}{\partial T^{2}}
$$

Generally, the dispersion and the nonlinearity act simultaneously along the fiber length. However, the Split Step Fourier method is based on an approximation, which consists in saying that over very short propagation distances $\mathrm{h}$, the operators $\hat{D}$ and $\hat{N}$ switch. The linear and non-linear effects act independently of one another and alternately. Solving the equation leads to two steps: the dispersive step and the nonlinear one.

The resolution of this equation in the frequency domain is as follows

$$
\hat{A}(z+h, \omega)=\hat{A}(z, \omega) \exp [h \widehat{D}]
$$

With the use of the inverse Fourier transform $T F^{-1}$, one can write the solution in the time domain as follows

$$
A^{\prime}(z+h, T)=T F^{-1}[\hat{A}(z, \omega) \exp [h \hat{D}(i \omega)]] .
$$

The operator $\hat{N}$ is then, applied in the time domain

$$
A(z+h, T)=A(z, T) \exp [h \hat{N}] .
$$

Finally, the solution of the Schrodinger equation becomes

$A^{\prime}(z+h, T)=\exp \left(h i \gamma\left[|A|^{2}\right]\right) T F^{-1}[\hat{A}(z, \omega) \exp [h \hat{D}(i \omega)]]$.

By repeating these two operations over the entire length of the fiber, we can realize a numerical simulation of the propagation of optical pulses in an optical fiber.

Over the last decades, many research studies have been accomplished with the aim to minimize the effects of soliton interactions and improve optical soliton communication systems by decreasing the bit rate error. The obvious solution consists in separating adjacent solitons by more than six times the temporal width of the pulse, but since exceeding the threshold/ limits is necessary, one cannot rely on the time interval. So the researchers proposed several solutions to avoid the collisions, such as the injection of solitons with different amplitudes [10], the introduction of Raman effect [11], the introduction of the third order dispersion, the good choice of the phase and many others among which we quote $[4,12,13]$. Thus, the suppression of the solitonic collisions using the chirp [14] has never been considered before.

In this paper, we invent a new category of solitons that never interact between them whatever is their temporal separation or their intensities or their order. These solitons are the result of the compensation of the nonlinearity with the temporal chirp instead of the GVD that produces the traditional solitons; for this reason we call this class of solitons "pure-chirped solitons". Our simulation results confirm that the application of the chirp on solitons in a nonlinear regime (noting that the regime is so-called a nonlinear regime when $\beta_{2}=0 \mathrm{ps}^{2} / \mathrm{km}$ ) guarantees a propagation completely free of interactions.

Experimentally, there are several methods for controlling or even canceling of the dispersion called 'dispersion management' or 'dispersion compensation' among which we cite the 'mode-locked lasers' method, which can generate dispersion managed solitons when this method is used with a suitable combination in optical fibers. Among the researchers who applied this technique, there are the authors of [15].

Our study is divided into three sections: firstly, we review the effect of the phase on a fundamental traditional soliton considered in [16], and then we have to study the effect of the chirp on solitons owning different values of GVD. Secondly, we apply the chirp to delete the collision of two co-propagating fundamental solitons in the absence of GVD; by this technique we generate the pure-chirped solitons. Finally, the chirp is applied on pure-chirped solitons with different amplitudes, phases and orders of solitons in the aim to check its ability to separate all kinds of pure-chirped solitons.

Results. The suppression of the interaction with the chirp. In this study, we focus on the influence of the chirp parameter 
value on two co-propagative solitons free of GVD, and the influence of the bit rate, the phase, the amplitude and the order of the solitons on the pure-chirped solitons. All the figures in this paper illustrate the propagation of the solitons on the three axes: the time $T$, the distance $Z$, and the intensity $I=$ $=|A(z, T)|^{2}$. The first two quantities are shown directly as two axes, but the last one is shown as a color bar next to the figures.

In the first study we review the effect of the chirp on the fundamental traditional soliton done by people in [16], (Fig. 1). Fig. 1 shows the propagation of a fundamental soliton in the presence of a positive chirp and a negative one respectively. From the results, we conclude that the chirp creates an irregular periodic compression because each period is shorter than the precedent one, beside the compression itself, which decreases in each period. The influence of the sign of the chirp is the position of the compressed points and their intensity. Notice that when the chirp is negative, the compression is higher in intensity and lasts longer than when the chirp is positive. On the other hand, the negative chirp creates a monotonic compression contrary to the propagation with a positive chirp.

In the next study, we precise the effect of the GVD on chirped solitons. Fig. 2 presents the results of the simulation of chirped solitons with different values of the GVD.

The decrease in the GVD leads to the decrease in the compression point. One can say that the number of the compressed points and their intensities is inversely proportional to the GVD. So the more the GVD decreases, the more compressed points appear with a higher intensity until it remains constant when the GVD is null, because the compression is applied on all the soliton length. For this reason, we try to keep the GVD null in the presence of the chirp to separate two co-propagative solitons and avoid the periodic attraction between them.

The propagation of co-propagative pure-chirped solitons. The propagation of the co-propagative pure-chirped solitons is shown with the simulation of the equation in Fig. 3.

$$
\begin{aligned}
A(z= & 0, T)=A_{0} \operatorname{sech}\left(T / T_{0}+\tau\right) \cdot e^{-i \cdot(C / 2)\left(T / T_{0}+\tau\right)^{2}}+ \\
& +A_{0} \operatorname{sech}\left(T / T_{0}-\tau\right) \cdot e^{-i \cdot(C / 2) \cdot\left(T / T_{0}-\tau\right)^{2}} .
\end{aligned}
$$

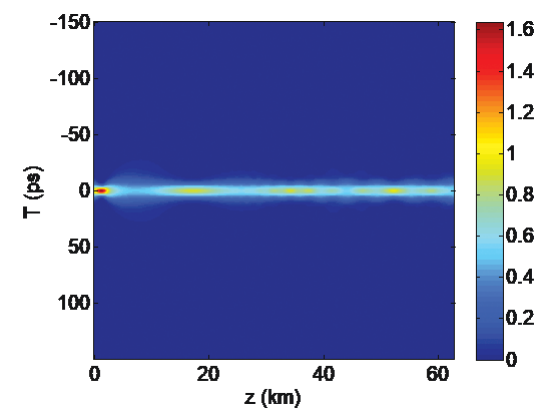

$a$

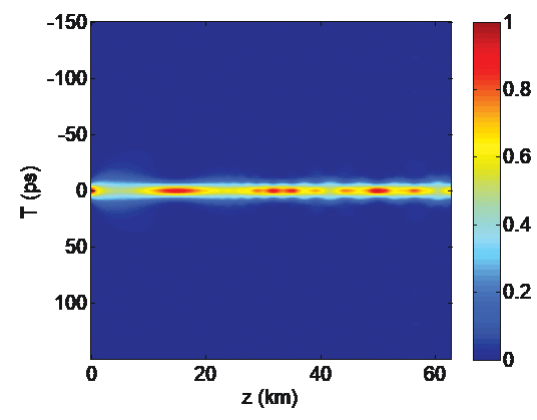

$b$

Fig. 1. The propagation of a fundamental soliton in the presence of a chirp:

$$
a-\left(\beta_{2}=-25 \mathrm{ps}^{2} / \mathrm{km}, C_{1}=0.5\right) ; b-\left(\beta_{2}=-25 \mathrm{ps}^{2} / \mathrm{km}, C_{2}=-0.5\right)
$$

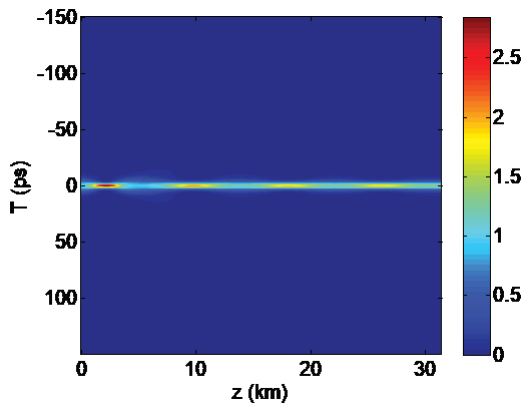

$a$

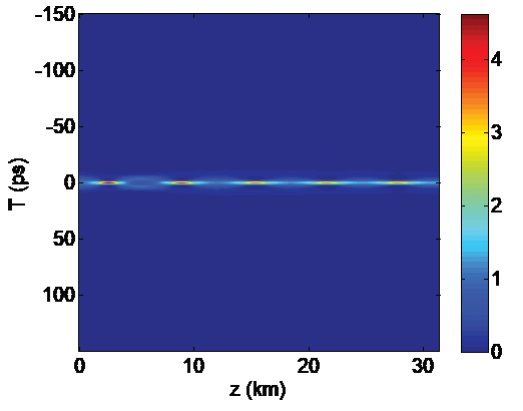

b

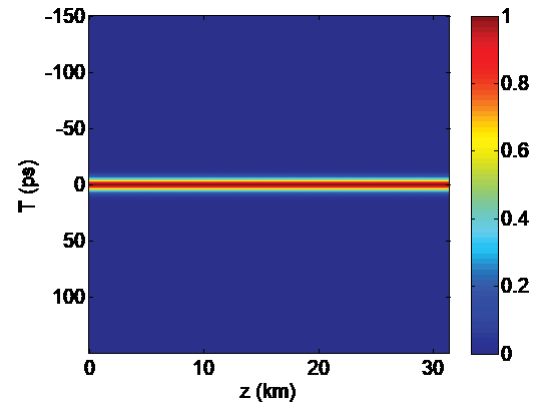

$c$

Fig. 2. The propagation of a fundamental soliton in the presence of a positive chirp and different values of $\beta_{2}$ : $a-\beta_{2}=12 p s^{2} / \mathrm{km} ; b-\beta_{2}=6 \mathrm{ps}^{2} / \mathrm{km} ; c-\beta_{2}=0 \mathrm{ps}^{2} / \mathrm{km}$

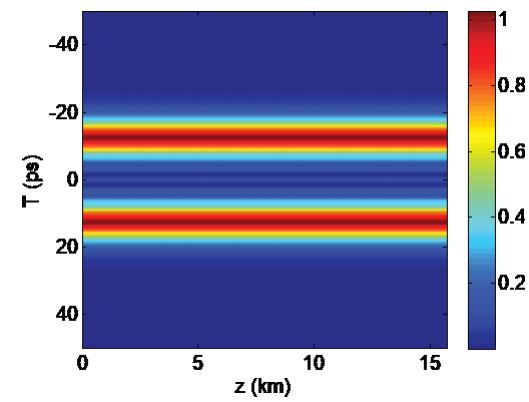

$a$

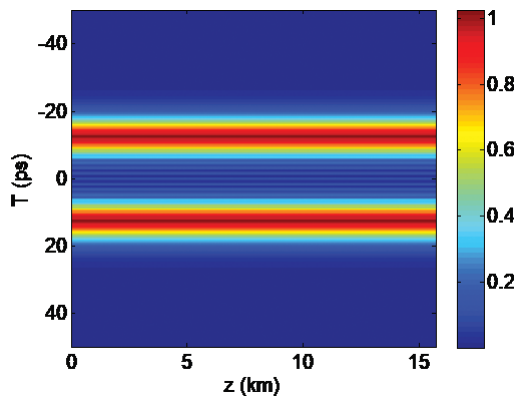

$b$

Fig. 3. The propagation of two fundamental pure-chirped solitons with different values of the positive chirp $C$ and the same temporal separation for $\beta_{2}=0 \mathrm{ps}^{2} / \mathrm{km}$ :

$a-C=2 ; \tau=2.5 ; b-C=4 ; \tau=2.5$ 
where $\tau=\Delta t_{0} / T_{0}$ depends on the initial temporal separation $\Delta t_{0}$.

We can see from the figures that there is no interaction between the pure-chirped solitons, thus there are some side lobs between the solitons, which are increasing with the increase in the chirp parameter.

We find that by keeping the chirp constant and varying the bit rate, we get more side lobs inside the two solitons when they are close to each other. Except the side lobs, the solitons characteristics remain the same: they keep the same intensity and half width, and a more interesting thing is that no interaction occurs.

The effect of different amplitudes on the pure-chirped solitons. The effect of different amplitudes on the pure-chirped solitons is done by using the equation.

The remark we made is that the propagation of two purechirped solitons with different amplitudes does not change anything regarding the interactions comparing with the purechirped solitons owning the same amplitudes (Fig. 4). We get the same side lobs, and the same separation between them.

$$
\begin{aligned}
A(z= & 0, T)=A_{0} \operatorname{sech}\left(T / T_{0}+\tau\right) \cdot e^{-i \cdot(C / 2)\left(T / T_{0}+\tau\right)^{2}}+ \\
& +A_{1} \operatorname{sech}\left(T / T_{0}-\tau\right) \cdot e^{-i \cdot(C / 2) \cdot\left(T / T_{0}-\tau\right)^{2}}
\end{aligned}
$$

The effect of the phase on the pure-chirped solitons. It is known that the phase has an important role in the solitonic interactions because it provokes either attraction or repulsion of the solitons. Here we review the effect of the phase on solitonic interactions in case of conventional solitons generated with the compensation of both GVD and the nonlinearity, in absence of the chirp, and for several values of the phase (Fig. 5). The equation used for those results is the equation

$$
\begin{aligned}
A(z= & 0, T)=A_{0} \operatorname{sech}\left(T / T_{0}+\tau\right) \cdot e^{\left(i \cdot \theta_{1}\right)}+ \\
& +A_{0} \operatorname{sech}\left(T / T_{0}-\tau\right) \cdot e^{\left(i \cdot \theta_{2}\right)},
\end{aligned}
$$

where $\theta_{1}$ and $\theta_{2}$ are the constant phases of the first and the second soliton respectively.

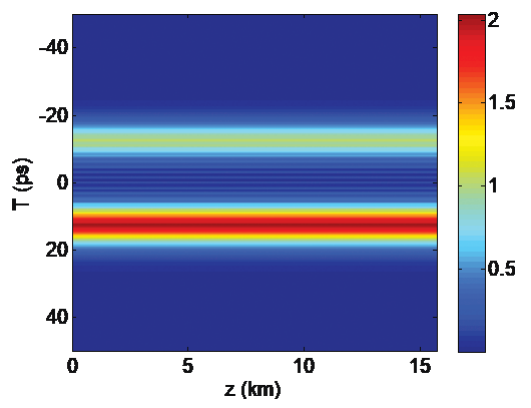

Fig. 4. The propagation of two fundamental pure-chirped solitons in the presence of a positive chirp with $C=4 ; \tau=2.5$ and different amplitudes

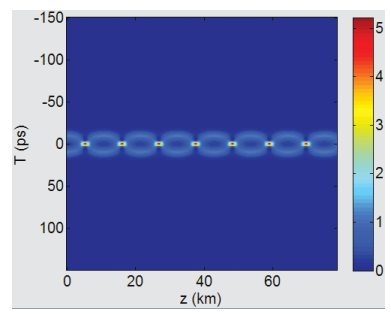

$a$

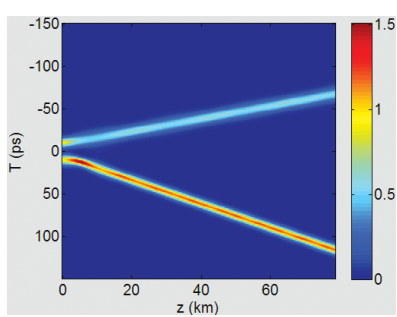

$b$

We found out that the solitons having opposite phases $\theta_{1}=$ $=-\theta_{2}$ undergo an attraction before the repulsion except for two cases $\left(\theta_{1}=\pi / 2\right.$ and $\left.\theta_{2}=-\pi / 2\right)$ or $\left(\theta_{1}=3 \pi / 2\right.$ and $\left.\theta_{2}=-3 \pi / 2\right)$. However, when the two opposite phases are equal to $\left(\theta_{1}=\pi / 2\right.$ and $\left.\theta_{2}=-\pi / 2\right)$ or $\left(\theta_{1}=3 \pi / 2\right.$ and $\left.\theta_{2}=-3 \pi / 2\right)$, they undergo a direct and symmetric repulsion, without any energy exchange between them because the amplitudes remain equal for two solitons, noting that the temporal shift is the same for both solitons (symmetric shift). Otherwise, for the other phase values, the repulsion is assymmetric: the leading pulse gets shifted more than the trailing pulse if $\left(\theta_{1}<\pi / 2\right.$ and $\left.\theta_{2}<-\pi / 2\right)$ and $\left(\theta_{1}>3 \pi / 2\right.$ and $\left.\theta_{2}>-3 \pi / 2\right)$ for this interval, the energy is transferred from the trailing to the leading pulse. If $\left(\pi / 2<\theta_{1}<3 \pi / 2\right.$ and $-\pi / 2>\theta_{2}>-3 \pi / 2$ ) the shift of the trailing pulse is higher than the leading pulse. The transferred energy is from the leading to the trailing pulse in the interval of $\left(\pi / 2<\theta_{1}<3 \pi / 2\right.$ and $\left.-\pi / 2>\theta_{2}>-3 \pi / 2\right)$.

In the case where two opposed phases are $\left(\theta_{1}=\pi\right.$ et $\theta_{2}=$ $=-\pi)$ or are both null, one obtains a periodic attraction. The scenario of the attraction is illustrated in Fig. 5. It shows that the attraction is symmetric and occurs without any shift or energy exchange between the solitons.

In the next, we want to see the effect of the phase on the chirped solitons in the absence of the GVD by the simulation of the equation

$$
\begin{aligned}
A(z= & 0, T)=A_{0} \operatorname{sech}\left(T / T_{0}+\tau\right) \cdot e^{-i \cdot(C / 2)\left(T / T_{0}+\tau\right)^{2}} \cdot e^{\left(i \cdot \theta_{1}\right)}+ \\
& +A_{0} \operatorname{sech}\left(T / T_{0}-\tau\right) \cdot e^{-i \cdot(C / 2) \cdot\left(T / T_{0}-\tau\right)^{2}} \cdot e^{\left(i \cdot \theta_{2}\right)} .
\end{aligned}
$$

The simulation results for two out-of-phase co-propagative solitons are shown in Fig. 6. As a result, we get the same propagation of two in-phase solitons: there is no attraction or repulsion between the two solitons. The interpretation of this phenomenon is that the chirp ends all the attractions or repulsions between the solitons because it is stronger than the interactions between their electric fields.

The propagation of higher order pure-chirped solitons. The closeness of two higher order traditional solitons leads to their fission into several fundamental solitons such as the number of the solitons generated is the same as the order of the soliton " $N$ ". Consequently, this decay destroys the shape of the higher order soliton but it can be useful for the generation of some special waves called 'supercontinuum'. This is physically interpreted by a huge attraction between the electric field of the two higher order solitons.

This fission begins after a certain distance named in the literature 'The fission distance $L_{S}$ '

$$
L_{S}=\frac{L_{D}}{N}=\sqrt{\frac{T_{0}}{\left|\beta_{2} \gamma A_{0}\right|}}
$$

Figs. 7 and 8 show the fission of the $3^{\text {rd }}$ and the $4^{\text {th }}$ order solitons in two cases in-phase and out-of-phase. We see from the figures that the phase has an effect on the fundamental solitons generated: in case of the same phase, the shift of fun-

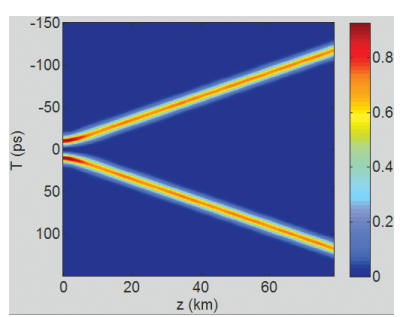

$c$

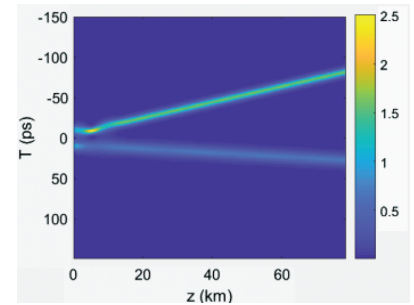

$d$

Fig. 5. The attraction and repulsion of two traditional solitons with different phases $\theta_{1}, \theta_{2}$ for:

$$
\beta_{2}=-25 \mathrm{ps}^{2} / \mathrm{km}, C_{1}=0 \text { and } C_{2}=0 ; a-\theta_{1}=\pi \text { and } \theta_{2}=-\pi ; b-\theta_{1}=\pi / 3 ; \theta_{2}=-\pi / 3 ; c-\theta_{1}=\frac{\pi}{2} ; \theta_{2}=-\frac{\pi}{2} ; d-\theta_{1}=1.2 \pi \theta_{2}=-1.2 \pi
$$




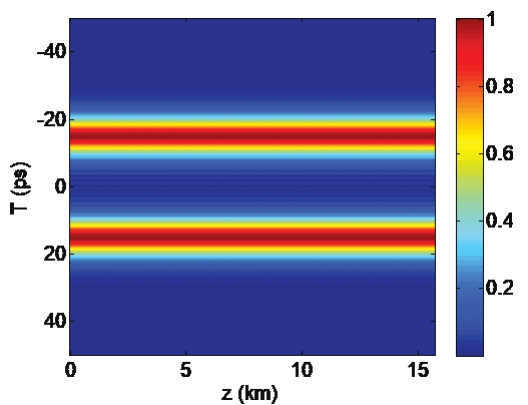

Fig. 6. The propagation of two fundamental pure-chirped solitons in the presence of a positive chirp with $C=3.5 ; \tau=2.5$ and different phases

damental soliton exists but remains constant so that the fundamental solitons generated look straight and they propagate symmetrically. Whereas in case of the opposite phase, the shift of the fundamental solitons generated is not constant. We also remark that there is no energy exchange between the fundamental solitons generated by the fission.

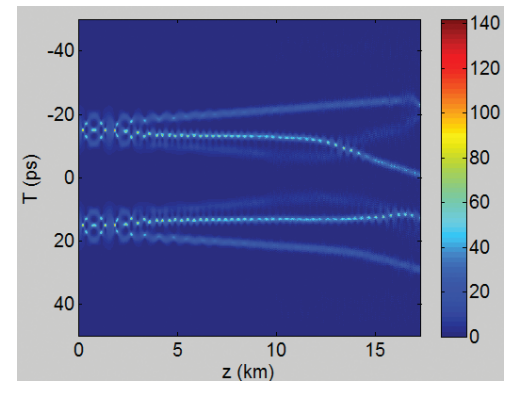

The propagation of the higher order pure-chirped solitons is shown in Fig. 9 by the simulation of the equation. The simulation is done for a null GVD and a non-null chirp.

$$
\begin{aligned}
A(z= & 0, T)=N^{2} \cdot A_{0} \operatorname{sech}\left(T / T_{0}+\tau\right) \cdot e^{-i \cdot(C / 2) \cdot\left(T / T_{0}+\tau\right)^{2}}+ \\
& +N^{2} \cdot A_{0} \operatorname{sech}\left(T / T_{0}-\tau\right) \cdot e^{-i \cdot(C / 2) \cdot\left(T / T_{0}-\tau\right)^{2}} .
\end{aligned}
$$

Conclusion. As a result, each higher order pure-chirped soliton loses its usual periodic shape, so we get two purechirped fundamental solitons with higher amplitude without any interactions, noting that the amplitude is equal to the order of the soliton in square. By comparing the figures, we see that the side lobes remain the same regardless of the order of the soliton. In addition, the half width remains the same for all different pure-chirped solitons orders; so, as a conclusion, the chirp is able to separate co-propagative higher order solitons in absence of GVD, and gives them the shape of a fundamental soliton multiplying its amplitude depending on the order of the pure-chirped soliton.

In this paper, we discussed the possibility of deleting solitons interaction thanks to the temporal chirp with the cancellation of the GVD. We concluded that the chirp is able

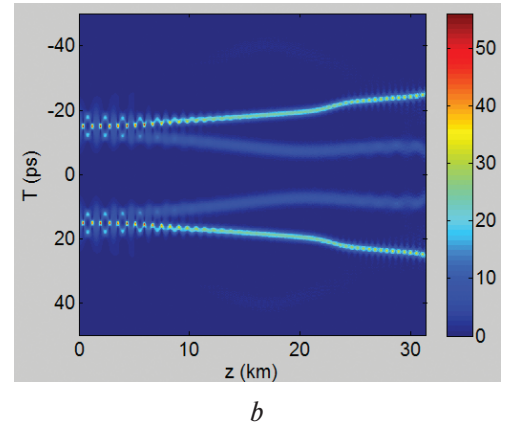

Fig. 7. The propagation of two out-of-phase solitons in the absence of the chirp with $\tau=3$ :

$a-a$ third order soliton $(N=3) ; b-a$ fourth order soliton $(N=4)$

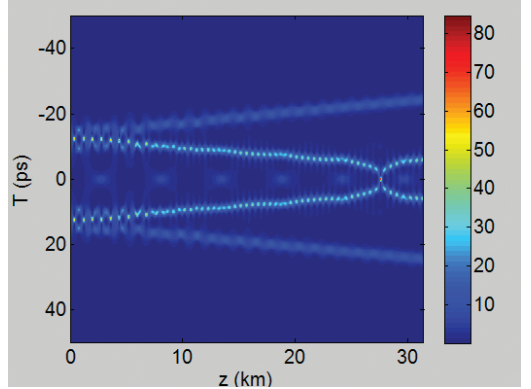

$a$

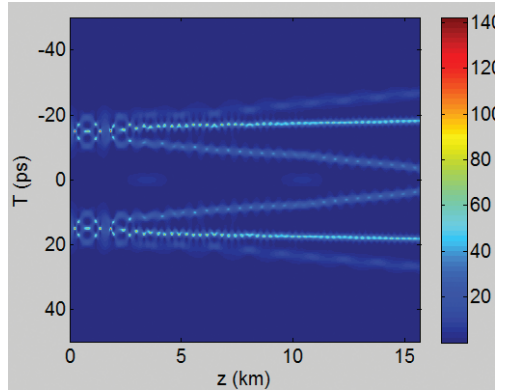

$b$

Fig. 8. The propagation of two in-phase solitons in the absence of the chirp with $\tau=3$ :

$a-a$ third order soliton $(N=3) ; b-a$ fourth order soliton $(N=4)$

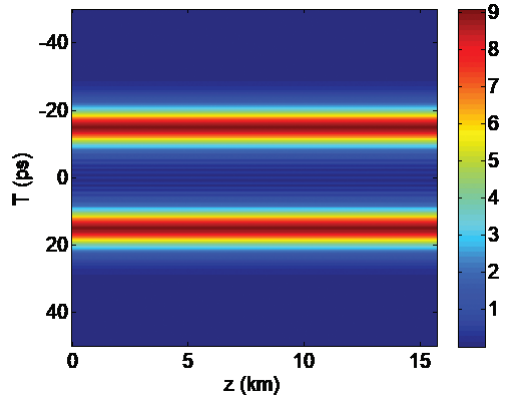

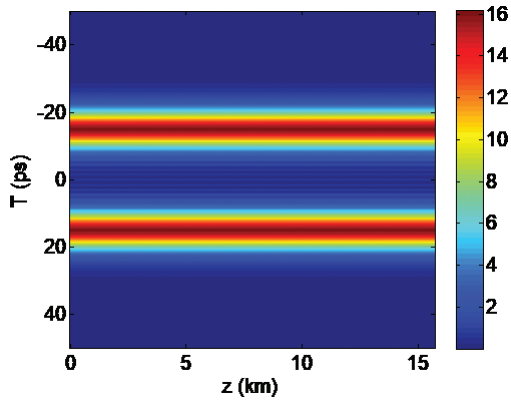

$b$

Fig. 9. The propagation of two solitons in the presence of a positive chirp with $C=3.5$ and $\tau=3$ :

$a-a$ third order soliton $(N=3) ; b-$ a fourth order soliton $(N=4)$ 
to separate the attractions and repulsions between adjacent solitons even if they have different phases, amplitudes, or orders.

\section{References.}

1. Govind, Agrawal (2012). Nonlinear Fiber Optics. Elsevier Science. Retrieved from: https://www.worldcat.org/title/nonlinear-fiber-optics/oclc/1003616272.

2. Boling Guo, Zaihui Gan, Linghai Kong, \& Jingjun Zhang (2016). The Zakharov System and its Soliton Solutions. Springer Singapore. https://doi.org/10.1007/978-981-10-2582-2.

3. Hasegawa, A., \& Kodama, Y. (1995). Solitons in optical communications. Oxford University Press, New York, Clarendon Press. ISBN: 0198565070.

4. Yang, C.Y., Li, W.Y., Yu, W.T., Liu, M.L., Zhang, Y.J., Ma, G. L., Lei, M., \& Liu, W. J. (2018). Amplification, reshaping, fission and annihilation of optical solitons in dispersion-decreasing fiber, Nonlinear Dynamics, 92, 203-213. https://doi.org/10.1007/s11071-018-4049-9.

5. Liu, W. J., Yang, C. Y., Liu, M. L., Yu, W. T., Zhang, Y. J., \& Lei, M. (2017). Effect of high-order dispersion on three-soliton interactions for the variable-coefficients Hirota equation. Physical Review E, 96, 042201. https://doi.org/10.1103/PhysRevE.96.042201.

6. Qiu, D., He, J., Zhang, Y., \& Porsezian, K. (2015). The Darboux transformation of the Kundu-Eckhaus equation. Proceedings of the Royal Society A. https://doi.org/10.1098/ rspa.2015.0236.

7. Elsayed, M. E. Zayed, \& Abdul-Ghani Al-Nowehy (2017). The solitary wave ansatz method for finding the exact bright and dark soliton solutions of two nonlinear Schrödinger equations. Journal of the Association of Arab Universities for Basic and Applied Sciences, 24(1), 184-190. https://doi.org/10.1016/j. jaubas.2016.09.003.

8. Wang, P., Tian, B., Liu, W. J., \& Sun, K. (2014). N-soliton solutions, Bäcklund transformation and conservation laws for the integro-differential nonlinear Schröbinger equation from the isotropic inhomogeneous Heisenberg spin magnetic chain. Computational Mathematics and Mathematical Physics, 54(4), 727-743.https://doi.org/10.1134/S0965542514040125. 9. Barbara Prinari, Alyssa K. Ortiz, Cornelis van der Mee, \& Marek Grabowski (2018). Inverse Scattering Transform and Solitons for Square Matrix Nonlinear Schrödinger Equation. Studies in Applied Mathematics. https://doi.org/10.1111/ sapm.12223.

10. Antwiwaa, A. (2012). Effect of Interaction Caused by Relative Phase, Amplitude and Spacing on Neighboring Soliton Pulses. Proceedings of the World Congress on Engineering, Vol IIWCE. London, 1-4. ISBN: 978-988-19252-1-3.

11. Prannay Balla, Shaival Buch, \& Govind P. Agrawal (2017). Effect of Raman scattering on soliton interactions in optical fibers. Rochester: The Institute of Optics, University of Rochester, New York 14627, USA, 34(6), 1247-1254. https://doi. org/10.1364/JOSAB.34.001247.

12. Rajeev Sharma (2014). Numerical simulations of collision behaviors of optical solitons in a Kerr law media. International Journal of Electronics, Communication \& Instrumentation Engineering Research and Development, 4(4), 51-54. ISSN(P): 2249-684X; ISSN(E): 2249-7951.

13. Chunyu Yang, Qin Zhou, Houria Triki, Mohammad Mirzazadeh, Mehmet Ekici, Wen-Jun Liu, Anjan Biswas, \& Milivoj Belic (2018). Bright soliton interactions in a (2+1)-dimensional fourth-order variable-coefficient nonlinear Schrödinger equation for the Heisenberg ferromagnetic spin chain. Nonlinear Dynamics, 95, 983-994. https://doi.org/10.1007/s11071018-4609-z.

14. Triki, H., Porsezian, K., \& Grelu, P. (2016). Chirped soliton solutions for the generalized nonlinear Schrödinger equation with polynomial nonlinearity and non-Kerr terms of arbitrary order. Journal of Optics, 18(7). https://doi. org/10.1088/2040-8978/18/7/075504.
15. Andrea Blanco-Redondo, C. Martijn de Sterke, J. E. Sipe, Thomas F. Krauss, Benjamin J. Eggleton, \& Chad Husko (2016). Pure-Quartic Solitons. Nature communications, 7, 10427. https://doi.org/10.1038/ncomms10427.

16. Senthilnathan, K., Nakkeeran, K., Qian Li, \& Wai, P. K. A. (2017). Chirped Optical Solitons. High Degree Pulse Compression. International Journal of Latest Engineering Research and Applications, 2(2), 49-53. ISSN: 2455-7137. https://doi. org/10.1109/OECC.2009.5214444.

\section{Вплив ЛЧМ-імпульсу на взаємодію солітонів із «чистою» лінійною частотною модуляцією}

\author{
Х.Хеліл ${ }^{1}$, К. Саоучі ${ }^{1}$, Д.Бахлул ${ }^{2}$
}

1 - Університет Баджі Мохтар - Аннаба, м. Аннаба, Алжир, email: khadidjapra@gmail.com

2 - Університет Хадж Лахдар - Батна, м. Батна, Алжир

Мета. Дослідити вплив ЛЧМ-імпульсу на взаємодію солітонів.

Методика. Щоб оцінити вплив ЛЧМ-імпульсу на взаємодію солітонів, наше дослідження сфокусовано на фундаментальних солітонах, модельованих на основі відомого нелінійного рівняння Шредінгера (НЛРШ), а також із використанням швидкого перетворення Фур'є. По-перше, ми розглядаємо вплив ЛЧМ-імпульсу, встановлюючи різні значення дисперсії групової швидкості (ДГШ) одного фундаментального солітону. По-друге, ми вводимо ЛЧМ-імпульс для двох фундаментальних солітонів, досить близьких для того, щоб створити Керріндуковану нелінійність; і за відсутності ДГШ досліджуємо його вплив на їх взаємодію. На закінчення, ми застосовуємо ЛЧМ-імпульс для двох фундаментальних солітонів з різними фазами, амплітудами й порядком солітонів, щоб порівняти його вплив на взаємодії у всіляких випадках.

Результати. ЛЧМ-імпульс є корисним для того, щоб виключити взаємодії за відсутності ДГШ.

Наукова новизна. Полягає у використанні ЛЧМімпульсу без ДГШ, для того, щоб розділити два солітона, які піддаються тяжінню або відштовхуванню.

Практична значимість. Дане дослідження показує, що за параметрів дисперсії групової швидкості $\beta_{2}=-25$ пс $^{2} / \mathrm{kм}$ і параметрі ЛЧМ-імпульсу $C_{1}=0,5$ або $C_{2}=-0,5\left(C_{1}, C_{2}-\right.$ коефіцієнти ЛЧМ-імпульсу першого та другого солітону відповідно) отримано додаткове періодичне стиснення. Далі ми поступово знижуємо ДГШ до нуля; тут ми виявляємо постійне стиснення замість періодичного. У висновку, ми розглядаємо вплив параметра ЛЧМ-імпульсу на два суміжних фундаментальних солітона для параметрів ЛЧМ-імпульсу $C=2,3$ і 4 із різними значеннями швидкості передачі бітів $\tau=2$ і 3 . На довершення всього, ми варіюємо вихідні параметри солітонів, такі як фаза, амплітуда й порядок солітонів.

Ключові слова: взаємодія солітонів, нелінійність, дисперсія, оптоволокно, канал передачі, тимчасовий ЛЧМімпульс

\section{Влияние ЛЧМ-импульса на взаимодействие солитонов с «чистой» линейной частотной модуляцией}

\author{
Х.Хелил ${ }^{1}$, К. Саоучи 1 , Д. Бахлул ${ }^{2}$
}

1 - Университет Баджи Мохтар - Аннаба, г. Аннаба, Алжир, email: khadidjapra@gmail.com

2 - Университет Хадж Лахдар - Батна, г. Батна, Алжир 
Цель. Исследовать влияние ЛЧМ-импульса на взаимодействие солитонов.

Методика. Чтобы оценить влияние ЛЧМ-импульса на взаимодействие солитонов, наше исследование сфокусировано на фундаментальных солитонах, моделируемых на основе известного нелинейного уравнения Шредингера (НЛУШ), а также с использованием быстрого преобразования Фурье. Во-первых, мы рассматриваем влияние ЛЧМ-импульса, устанавливая различные значения дисперсии групповой скорости (ДГС) одного фундаментального солитона. Во-вторых, мы вводим ЛЧМ-импульс для двух фундаментальных солитонов, достаточно близких для того, чтобы создать Керр-индуцированную нелинейность; и при отсутствии ДГС исследуем его влияние на их взаимодействие. В заключение, мы применяем ЛЧМ-импульс для двух фундаментальных солитонов с разными фазами, амплитудами и порядком солитонов, чтобы сравнить его влияние на взаимодействия во всевозможных случаях.

Результаты. ЛЧМ-импульс является полезным для того, чтобы исключить взаимодействия при отсутствии ДГС.

Научная новизна. Состоит в использовании ЛЧМимпульса без ДГС, для того, чтобы разделить два солито- на, которые подвергаются притяжению или отталкиванию.

Практическая значимость. Данное исследование показывает, что при параметре дисперсии групповой скорости $\beta_{2}=-25$ пс $^{2} /$ км и параметре ЛЧМ-импульса $C_{1}=0,5$ или $C_{2}=-0,5\left(C_{1}, C_{2}-\right.$ коэффициенты ЛЧМ-импульса первого и второго солитона соответственно) получено дополнительное периодическое сжатие. Далее мы постепенно снижаем ДГС до нуля; здесь мы обнаруживаем постоянное сжатие вместо периодического. В заключении, мы рассматриваем влияние параметра ЛЧМ-импульса на два смежных фундаментальных солитона для параметров ЛЧМ-импульса $C=2,3$ и 4 с разными значениями скорости передачи битов $\tau=2$ и 3 . В довершение всего, мы варьируем исходные параметры солитонов, такие как фаза, амплитуда и порядок солитонов.

Ключевые слова: взаимодействие солитонов, нелинейность, дисперсия, оптоволокно, канал передачи, временный ЛЧМ-импульс

Recommended for publication by Dr. Aissa Benselhoub. The manuscript was submitted 01.04.19. 